Review began 01/14/2022 Review ended 01/20/2022 Published 01/28/2022

๑) Copyright 2022

Jamal et al. This is an open access article distributed under the terms of the Creative Commons Attribution License CC-BY 4.0. which permits unrestricted use, distribution, and reproduction in any medium, provided the original author and source are credited.

\section{A Rare Case of Multidrug-Resistant Tuberculosis Affecting the Pleura}

\author{
Khalid Jamal $^{1}$, Muhammad Imran ${ }^{2,3}$, Shah Hassan Khan ${ }^{1}$, Abdul Muneem ${ }^{1}$, Muhammad Salman Khan $^{4}$ \\ 1. Pulmonology, Saidu Teaching Hospital, Swat, PAK 2. Pulmonary and Critical Care, Lady Reading Hospital, Peshawar, \\ PAK 3. Pulmonology and Critical Care, COVID-19 Hospital, Peshawar, PAK 4. General Practice, Medical Emergency and \\ Resilience Foundation, Peshawar, PAK
}

Corresponding author: Muhammad Imran, drimransth@gmail.com

\begin{abstract}
The majority of cases with tuberculous pleuritis have negative acid-fast bacilli (AFB) on smear microscopy, making the diagnosis difficult. This case report is based on the successful diagnosis and management of an extra-pulmonary (EP) multidrug-resistant tuberculosis (MDR-TB) patient with a history of lymphoma. Initial tests revealed a right-sided pleural effusion and thickening of the pleura. The closed pleural biopsy, pleural fluid histopathology, culture, and drug sensitivity testing (DST) report revealed Mycobacterium tuberculosis with isoniazid and rifampicin resistance. Based on the DST report, the patient was labeled as a case of MDRTB and successfully managed with an individualized drug-resistant TB (DR-TB) regimen. With initial negative microscopy and GeneXpert MTB/RIF (Sunnyvale, CA: Cepheid Inc.) reports, this case demonstrated that DR-TB could exist even in the absence of risk factors. Furthermore, it also unveils the importance of line probe assays (LPAs) and culture in identifying MDR-TB. Lymphocytic/exudative pleural effusions and pleural biopsy specimens should be subjected early on to investigations like Xpert/MTB RIF, cultures, and genotypic DST to timely diagnose and treat DR-TB.
\end{abstract}

Categories: Infectious Disease, Pulmonology, Epidemiology/Public Health

Keywords: multidrug-resistant tb, line probe assays (lpa), isoniazid resistance, rifampicin resistance, mdr-tb, tuberculosis, pleural effusion, extra-pulmonary tuberculosis

\section{Introduction}

Pleura is one of the most common sites of extra-pulmonary tuberculosis (EP-TB), which occurs in approximately 5\% of people infected with Mycobacterium tuberculosis (MTB) [1]. In TB-endemic areas, however, the prevalence reaches up to $30 \%$ [2]. Diagnosis is complex, with $48-96 \%$ of tuberculous pleural effusions being negative by acid-fast bacilli (AFB) microscopy and culture. Thoracentesis is frequently performed and reveals an exudative, lymphocytic pleural effusion in more than $90 \%$ of patients, whereas direct investigation reveals AFB in less than $10 \%$ of patients [3]. More invasive diagnostic procedures are usually required because of the low specificity and sensitivity of AFB staining and cultures. We present a case that demonstrates the clinical presentation and diagnostic approaches of primary extra-pulmonary MDR-TB in an HIV-negative older adult with right-sided pleural effusion.

\section{Case Presentation}

A general practitioner (GP) referred a 50-year-old male patient to Programmatic Management of DrugResistant Tuberculosis (PMDT) unit Swat, Pakistan, with chief complaints of fever, anorexia, fatigue, and a $15 \mathrm{~kg}$ weight loss in one-month duration. The patient also attested to right-sided chest pain. On examination, he was ill-looking, pale, and had decreased air entry on the right side with dull percussion notes. The temperature was $101^{\circ} \mathrm{F}$ and blood pressure was $110 / 70 \mathrm{mmHg}$. He was treated with antibiotics and analgesics for lower respiratory tract infection without proper workup. A chest $\mathrm{x}$-ray posteroanterior (PA view) was performed which showed blunting of right costophrenic angle as shown in Figure 1, panel A. 


\section{Cureus}
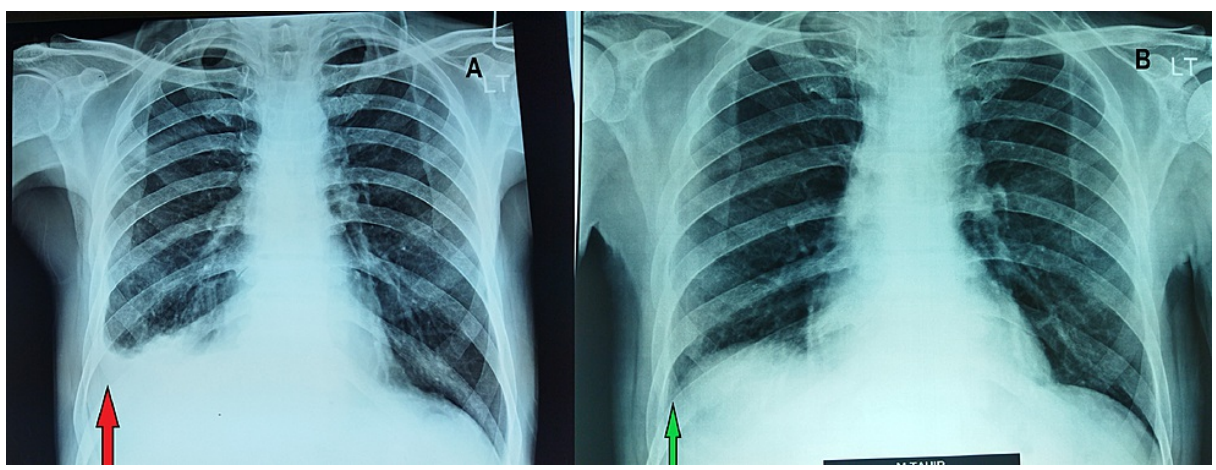

FIGURE 1: Pre- and post-treatment chest x-ray PA view.

(A) Pre-treatment CXR-PA view with blunting of right costophrenic angle (green arrow), which is a sign of effusion (B) The effusion has resolved completely, with a normal costophrenic angle (red arrow) in the follow-up CXR-PA view at sixth month of treatment.

PA: posteroanterior; CXR: chest x-ray

He has had a significant past medical history. Fifteen years before his current presentation, the patient presented to the medicine outpatient department (OPD) with generalized lymphadenopathy. Cervical lymph nodes were biopsied, and the histopathology showed chronic non-specific inflammation. He was started empirically on antitubercular therapy (ATT). After taking ATT for three months, the non-resolving cervical lymph nodes were re-excised, which showed Hodgkin's lymphoma. The patient was treated successfully as a case of lymphoma with chemotherapy and his symptoms resolved entirely.

An ultrasound-guided diagnostic pleural tap indicated a right-sided pleural effusion, as shown in Figure 1, panel A. Two pleural fluid samples and a closed pleural biopsy were collected using Abram's needle, followed by therapeutic aspiration of the fluid. One pleural fluid sample was submitted to the National Reference Laboratory (NRL) for GeneXpert (Sunnyvale, CA: Cepheid Inc.), AFB culture, and genotypic drug sensitivity testing (DST). The other sample was sent to the hospital laboratory for routine examination, conventional cytology, Gram staining, and culture. It was found to be a lymphocytic exudative effusion. No malignant cells were found. Moreover, bacterial cultures were negative after 48 hours, and histopathology was inconclusive. NRL provided genotypic DST utilizing the MTBDR-plus (Nehren, Germany: Hain Lifescience $\mathrm{GmbH}$ ) line probe assay (LPA), which showed a rpoB 530-533 rifampicin mutation, and an isoniazid mutation in KatG-S315T1, and the patient was labeled as having extra-pulmonary MDR-TB (Table 1). Both fluoroquinolones and second-line injectable's results were indeterminate.

\begin{tabular}{|c|c|c|c|c|c|c|c|c|}
\hline $\begin{array}{l}\text { Specimen } \\
\text { type }\end{array}$ & Appearance & Volume & AFB & \multicolumn{5}{|c|}{ Genotypic drug susceptibility test performed on LPA MTBDR-plus } \\
\hline \multirow{5}{*}{$\begin{array}{l}\text { Pleural } \\
\text { fluid }\end{array}$} & \multirow{5}{*}{ Turbid } & \multirow{5}{*}{$5.0 \mathrm{ml}$} & \multirow{5}{*}{$\begin{array}{l}\text { AFB smear- } \\
\text { negative }\end{array}$} & Drug & $\begin{array}{l}\text { Resistance } \\
\text { predicted }\end{array}$ & $\begin{array}{l}\text { Resistant } \\
\text { Gene }\end{array}$ & $\begin{array}{l}\text { Mutation } \\
\text { detected }\end{array}$ & Results interpretation \\
\hline & & & & Rifampicin & Resistance inferred & rpoB & $530-533$ & Rifampicin is not effective \\
\hline & & & & Isoniazid & $\begin{array}{l}\text { High-level } \\
\text { resistance detected }\end{array}$ & katG & S315T & $\begin{array}{l}\text { Isoniazid is unlikely to be effective } \\
\text { even at high dose }\end{array}$ \\
\hline & & & & Fluoroquinolones & Indeterminate & & & \\
\hline & & & & $\begin{array}{l}\text { Second-line } \\
\text { injectable drugs }\end{array}$ & Indeterminate & & & \\
\hline
\end{tabular}

\section{TABLE 1: Genotypic DST (MTBRsI-plus) result.}

Result of LPA MTBDR-plus, there was resistance inferred and detected to rifampicin and Isoniazid, respectively. Resistance to fluoroquinolones and second-line injectable drugs were reported as indeterminate.

LPA: line probe assay; MTBDR: Mycobacterium tuberculosis drug-resistant; AFB: acid-fast bacilli; DST: drug sensitivity testing

The patient was started on an individualized treatment regimen. Initial doses were, $1000 \mathrm{mg}$ levofloxacin, 


\section{Cureus}

$600 \mathrm{mg}$ linezolid, $100 \mathrm{mg}$ clofazimine, $750 \mathrm{mg}$ cycloserine, $1600 \mathrm{mg}$ pyrazinamide, $750 \mathrm{mg}$ ethionamide, and $150 \mathrm{mg}$ Vita-6. According to his psychiatric evaluation, his protracted sickness had left him somewhat depressed. He was motivated to cooperate with treatment and began psychotherapy. We employed incremental muscular relaxation, distraction, and deep breathing.

He was seen biweekly for the first month, then monthly. Each appointment included a psychological examination, which included a recap of the prior session. After three months of medication, the right-sided pleural effusion vanished, and the patient's chest x-ray and clinical condition remarkably improved (Figure 1, panel B).

The initial phase of linezolid and ethionamide was completed, and they were stopped at sixth month, while the rest of the therapy was continued for 12 more months. The patient had no recurrence of his pleural effusion till the last follow-up. The patient's closed contacts were counseled and screened regularly for any evidence of TB. No one was found positive or having any symptoms of TB.

\section{Discussion}

TB is one of the major public health issues in Pakistan; according to the Global TB Report, Pakistan ranks fifth among 30 high-burden nations for drug-sensitive TB (DS-TB) and fifth for drug-resistant TB (DR-TB) [4]. The causes of DR-TB include poor adherence to treatment, the use of low-quality medicine in the private sector, diagnostic delays, unsupervised therapy, and inadequate follow-up [5]. According to reports, DR-TB was discovered in $3-4 \%$ of new pulmonary cases and $18-21 \%$ of previously treated patients [6]. Furthermore, there is scarce data on extra-pulmonary drug-resistant tuberculosis in the literature. Table 2 shows the published cases according to PubMed Central. Yadav and Rawal reported similar cases of MDR-TB in the pediatric age group with pleura involvement [7]. As shown in Table 2, Anastasakos et al. found 103 cases of tubercular pleural effusion (TPE), with 11 showing DR-TB patterns [8]. Among them three showed resistance to isoniazid (INH), three were labeled as MDR-TB, one was extended drug-resistant TB (XDR-TB) and, seven showed other patterns of resistance. As a result, we have reported the first adult case of primary MDR-TB manifesting as pleural effusion, which has not previously been reported.

\begin{tabular}{|c|c|c|c|c|c|}
\hline S.NO & Authors & $\begin{array}{l}\text { Year of } \\
\text { publication }\end{array}$ & Journal & Sample size & $\begin{array}{l}\text { Resistance } \\
\text { pattern }\end{array}$ \\
\hline 1 & $\begin{array}{l}\text { Yadav and } \\
\text { Rawal [7] }\end{array}$ & 2016 & Iransnatıonal Pedıatrıcs & 1 & $\begin{array}{l}\text { Rifampicin and } \\
\text { INH }\end{array}$ \\
\hline 2 & $\begin{array}{l}\text { Anastasakos } \\
\text { et al. [8] }\end{array}$ & 2017 & $\begin{array}{l}\text { The International Journal of } \\
\text { Tuberculosis and Lung Disease }\end{array}$ & $\begin{array}{l}\text { Total: } 4391 \text {, pleural TB: } 103 \text {, and DR- } \\
\text { TB pleural effusion: } 11\end{array}$ & $\begin{array}{l}\text { MDR: } 3, \text { XDR: } 1 \text {, } \\
\text { others: } 7\end{array}$ \\
\hline 3 & Olson [9] & 2019 & Open Forum Infectious Diseases & 1 & INH \\
\hline
\end{tabular}

TABLE 2: Drug-resistant tubercular pleural effusion: published research.

DR-TB: drug-resistant tuberculosis, MDR: multidrug-resistant tuberculosis, XDR: extended drug-resistant tuberculosis; INH: isoniazid

Even though our patients' HIV testing was negative, all patients with extra-pulmonary TB should be screened for HIV infection because positive HIV status has been linked to increased risk of both DS- and DRTB [10]. Furthermore, in the case of EP-TB infections, where the diagnosis may be based solely on clinical and early laboratory results without final microbiological confirmation, a higher index of suspicion is usually required [11]. Diagnosis of any form of tuberculosis, particularly extra-pulmonary DR-TB, can be difficult for physicians at times. As in our case, the diagnosis was delayed because of negative smear microscopy and Xpert MTB/RIF results. Likewise, using biomarkers to aid in diagnosing increases the risk of incorrectly treating DS-TB as DR-TB [12]. As discussed, diagnosing MDR-TB in non-pulmonary samples is challenging and leads to high mortality and morbidity. Early identification of the TB strain through LPA and culture resulted in the successful management of the case and reduced the risk of complications.

\section{Conclusions}

Clinical factors and chest radiographic findings associated with MDR-TB should prompt physicians to perform Xpert MTB/RIF and DST sooner, as the patient is at risk of developing pulmonary or extrapulmonary DR-TB if an early diagnosis is not made. As a result, we recommend using GeneXpert MTB/RIF as a primary diagnostic technique on most tissue specimens in resource-limited settings. Moreover, cultures should be done in all cases where DR-TB is suspected, as, at times, rapid tests like Xpert MTB/RIF and microscopy are negative in cases of EP-TB. 


\section{Additional Information \\ Disclosures}

Human subjects: Consent was obtained or waived by all participants in this study. Institutional Review Board of Saidu Teaching Hospital issued approval N/A. Conflicts of interest: In compliance with the ICMJE uniform disclosure form, all authors declare the following: Payment/services info: All authors have declared that no financial support was received from any organization for the submitted work. Financial relationships: All authors have declared that they have no financial relationships at present or within the previous three years with any organizations that might have an interest in the submitted work. Other relationships: All authors have declared that there are no other relationships or activities that could appear to have influenced the submitted work.

\section{References}

1. Seibert AF, Haynes J Jr, Middleton R, Bass JB Jr: Tuberculous pleural effusion. Twenty-year experience. Chest. 1991, 99:883-6. 10.1378/chest.99.4.883

2. Diacon AH, Van de Wal BW, Wyser C, Smedema JP, Bezuidenhout J, Bolliger CT, Walzl G: Diagnostic tools in tuberculous pleurisy: a direct comparative study. Eur Respir J. 2003, 22:589-91. 10.1183/09031936.03.00017103a

3. Lin MT, Wang JY, Yu CJ, Lee LN, Yang PC: Mycobacterium tuberculosis and polymorphonuclear pleural effusion: incidence and clinical pointers. Respir Med. 2009, 103:820-6. 10.1016/j.rmed.2008.12.023

4. Ali S, Khan MT, Khan AS, et al.: Prevalence of multi-drug resistant Mycobacterium tuberculosis in Khyber Pakhtunkhwa - a high Tuberculosis endemic area of Pakistan. Pol J Microbiol. 2020, 69:1-5. 10.33073/pjm2020-005

5. Pradipta IS, Idrus LR, Probandari A, Lestari BW, Diantini A, Alffenaar JC, Hak E: Barriers and strategies to successful tuberculosis treatment in a high-burden tuberculosis setting: a qualitative study from the patient's perspective. BMC Public Health. 2021, 21: 10.1186/s12889-021-12005-y

6. Naz F, Ahmad N, Wahid A, et al.: High rate of successful treatment outcomes among childhood rifampicin/multidrug-resistant tuberculosis in Pakistan: a multicentre retrospective observational analysis. BMC Infect Dis. 2021, 21:10.1186/s12879-021-06935-6

7. Yadav S, Rawal G: Primary extrapulmonary multidrug-resistant tuberculosis in an immunocompetent child presenting with pleural effusion. Transl Pediatr. 2017, 6:72-5. 10.21037/tp.2016.07.01

8. Anastasakos V, Skouras V, Moschos C, et al.: Patterns of drug resistance among patients with tuberculous pleural effusion in Greece. Int J Tuberc Lung Dis. 2017, 21:309-13. 10.5588/ijtld.16.0155

9. Olson G, Nathavitharana RR, Lederer PA: Diagnostic delays and treatment implications for patients with isoniazid-resistant tuberculosis: a case report and review of the literature. Open Forum Infect Dis. 2019, 6:10.1093/ofid/ofz222

10. Singh A, Prasad R, Balasubramanian V, Gupta N: Drug-resistant tuberculosis and HIV infection: current perspectives. HIV AIDS (Auckl). 2020, 2020:9-31. 10.2147/HIV.S193059

11. Arega B, Mersha A, Minda A, Getachew Y, Sitotaw A, Gebeyehu T, Agunie A: Epidemiology and the diagnostic challenge of extra-pulmonary tuberculosis in a teaching hospital in Ethiopia. PLoS One. 2020, 15:10.1371/journal.pone.0243945

12. Trajman A, Pai M, Dheda K, et al.: Novel tests for diagnosing tuberculous pleural effusion: what works and what does not?. Eur Respir J. 2008, 31:1098-106. 10.1183/09031936.00147507 